\title{
Effects of Aging Treatment on Microstructure of High-Al-content Fe-15Mn-10Al-1.0C Alloy
}

\author{
Wei-Chih Chen, ${ }^{*}$ Chung-Chun Wu, ${ }^{2}$ and Wei-Yang Chang ${ }^{2}$ \\ ${ }^{1}$ Electrical and Mechanical Technology Department, Southern Taiwan University of Science and Technology, \\ No. 1, Nantai St., Yongkang Dist., Tainan City 710, Taiwan, R.O.C. \\ ${ }^{2}$ Mechanical Engineering Departments, Southern Taiwan University of Science and Technology, \\ No. 1, Nantai St., Yongkang Dist., Tainan City 710, Taiwan, R.O.C.
}

(Received July 29, 2017; accepted November 2, 2017)

Keywords: Fe-Mn-Al-C alloy, $\mathrm{B}_{2}$ and $\mathrm{D}_{3}$ ordered phases, spinodal decomposition

The purpose of this study is to examine the effects of aging treatment on the microstructures of the dual-phase Fe-15Mn-10Al-1.0C alloy by optical microscopy (OM) and transmission electron microscopy (TEM). On the basis of the results of our experiments, we reached the following conclusions. Under the as-quenched condition, the microstructure of the Fe- $15 \mathrm{Mn}$ 10Al-1.0C alloy was a mixture of ferrite and austenite phases. TEM examination revealed that $(\mathrm{Fe}, \mathrm{Mn}) 3 \mathrm{AlC}_{X}$ carbides precipitated within the austenite matrix, and $\left(\mathrm{B}_{2}+\mathrm{D}_{3}\right)$ ordered phases could be found within the ferrite region owing to the mechanism of the $\alpha \rightarrow \alpha+\mathrm{B}_{2} \rightarrow \alpha+\mathrm{D}_{3}$ ordering transition. This result indicated that an increase in the amount of $\mathrm{Al}$ added to the FeMn-Al-C alloy would enhance both the formation of ordered phases within the ferrite matrix and the precipitation of $\kappa$-carbides within the austenite matrix. When the alloy was aged at 650 ${ }^{\circ} \mathrm{C}$ for $24 \mathrm{~h}$, phase decomposition of $\gamma \rightarrow \kappa^{\prime}+\mathrm{B}_{2}$ was observed on the austenite grain boundary.

\section{Introduction}

Recently, Fe-Mn-Al-C alloys have been successfully developed for some specialized applications, such as high-strength alloy plates, cold-rolled plates, alloy bars, metal inert gas (MIG) welding wires, high-temperature furnace strips, golf clubs, and precision industrial castings. Several patents concerning Fe-Mn-Al-C alloys have been granted, indicating that the Fe-MnAl-C alloys have great potential for specific applications. ${ }^{(1-4)}$

A considerable amount of interest has focused on the effects of various alloying elements and of aging conditions on the microstructure changes and mechanical properties of $\mathrm{Fe}-\mathrm{Mn}$ Al-C alloys. To date, most examinations have been focused on the effects of $\mathrm{Si}, \mathrm{Ti}, \mathrm{Mo}, \mathrm{Cu}, \mathrm{Nb}$, $\mathrm{Ni}$, and $\mathrm{Cr}$ additions as well as the different aging processes in the Fe-Mn-Al-C alloy. However, there has been little investigation into the effects of aging treatment on high-Al-content Fe-MnAl-C alloy. Therefore, the purpose of this study is to examine the effects of aging treatment on the microstructure and mechanical properties of the Fe-15Mn-10Al-1.0C alloy by transmission electron microscopy (TEM). ${ }^{(5-8)}$ 


\section{Experimental Procedures}

Fe-15Mn-10Al-1.0C alloy ingots were prepared in an air induction furnace. After being homogenized at $1200{ }^{\circ} \mathrm{C}$ for $24 \mathrm{~h}$, the ingots were hot-forged and then cold-rolled to a final thickness of $30 \mathrm{~mm}$. The sheets were subsequently solution-heat-treated at $1050{ }^{\circ} \mathrm{C}$ for $1 \mathrm{~h}$ and rapidly quenched in room-temperature water. The aging processes were carefully performed at temperatures ranging from 450 to $750{ }^{\circ} \mathrm{C}$ for various durations in salt baths and then the ingots were quenched in water.

Specimens for TEM were prepared by means of a double-jet electrolyte of $10 \%$ perchloric acid, 30\% acetic acid, and 60\% ethanol. The polishing temperature was kept in the range from -10 to $0{ }^{\circ} \mathrm{C}$, and the current was kept in the range of 30 to $40 \mathrm{~mA}$. Electron microscopy was performed using a Philips FEG-20 scanning transmission electron microscope (STEM) operating at $200 \mathrm{kV}$.

\section{Results and Discussion}

Under the as-quenched condition, the microstructure of the Fe-15Mn-10Al-1.0C alloy was a mixture of ferrite and austenite phases, as shown in Fig. 1(a). When comparing Fe-15Mn-8Al1.0C alloy and Fe-15Mn-10Al-1.0C alloy under the as-quenched condition, it was found that the Fe-15Mn-8Al-1.0C alloy was a mixture of only austenite phases, as shown in Fig. 1(b), because an increase in the amount of $\mathrm{Al}$ in the Fe-Mn-Al-C alloy causes ferrite phase stabilization. The microstructure was further observed by TEM. Figures 2 and 3 are electron micrographs of the Fe-15Mn-10Al-1.0C alloy under the as-quenched condition. Figure 2(a) is the selected area diffraction pattern (SADP) of the austenite matrix, where the foil normal is [001], and it shows the existence of austenite matrix diffraction spots and the precipitate of $\kappa$-carbide diffraction spots. Figure 2(b) is the dark-field (DF) electron micrograph of the (100) $\kappa$-carbide precipitate spot in Fig. 2(a), revealing the precipitation of $(\mathrm{Fe}, \mathrm{Mn})^{3} \mathrm{AlC} \mathrm{C}_{X}$ carbides having a L'12 crystal structure, which could be observed within the austenite matrix. ${ }^{(3-5)}$ Figures 3(a) and 3(b) are the SADPs of the ferrite region, where the foil normals are [001] and [011], respectively, showing

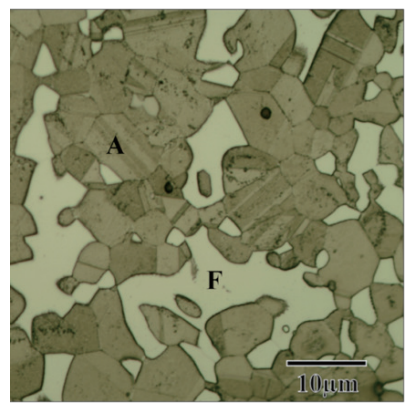

(a)

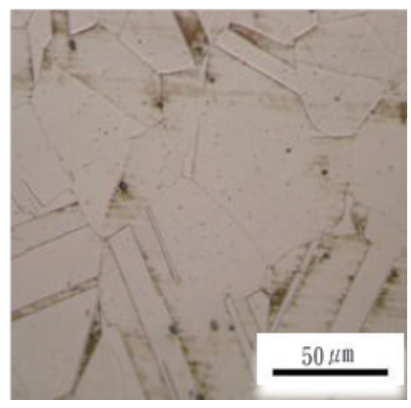

(b)

Fig. 1. (Color online) Optical micrograph of Fe-Mn-Al-C alloys after solution heat treatment at $1050{ }^{\circ} \mathrm{C}$ for $1 \mathrm{~h}$. (a) Fe-15Mn-10Al-1.0C and (b) Fe-15Mn-8Al-1.0C. 


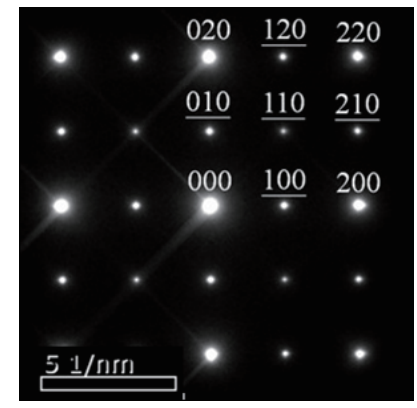

(a)

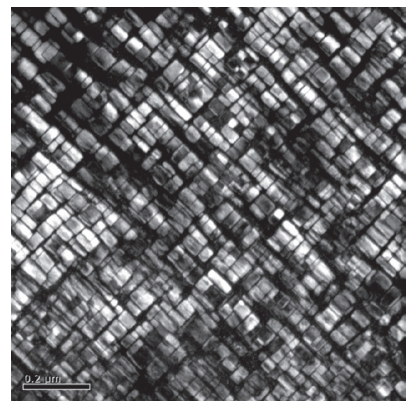

(b)

Fig. 2. TEM images of Fe-15Mn-10Al-1.0C alloy under the as-quenched condition. (a) SADP of the austenite matrix. The foil normal is [001]. (b) (100) $\kappa$-carbide DF electron micrograph.

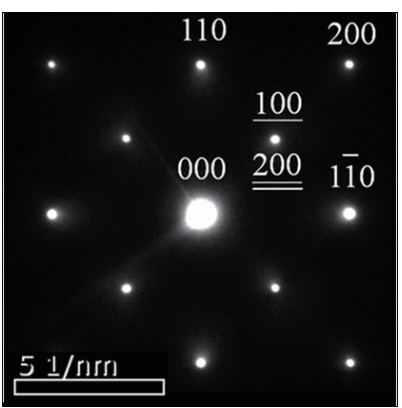

(a)

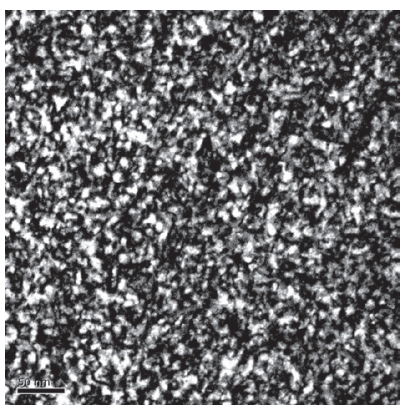

(c)

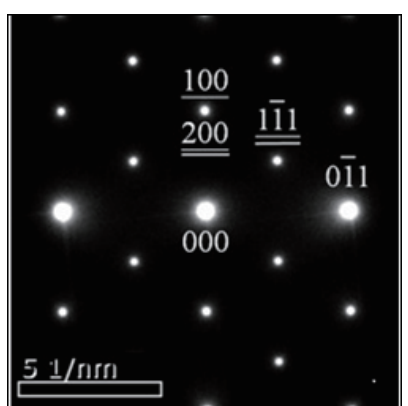

(b)

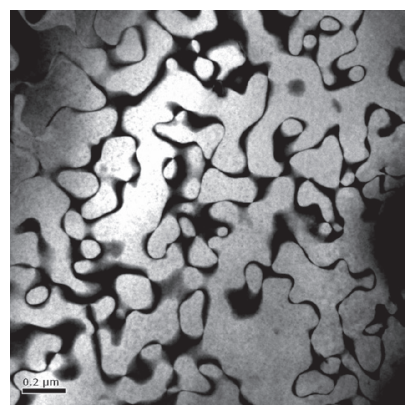

(d)

Fig. 3. TEM images of Fe-15Mn-10Al-1.0C alloy under the as-quenched condition. SADPs of the ferrite matrix where (a) the foil normal is [001] and (b) the foil normal is [011]. DF electron micrographs of (c) the (111) $\mathrm{D}_{3}$ phase and (d) the (200) $\mathrm{D}_{3}$ and (100) $\mathrm{B}_{2}$ phases.

the existence of ferrite matrix diffraction spots and the precipitate of $\mathrm{B}_{2}$ and $\mathrm{D}_{3}$ diffraction spots. Figure 3(c) is the DF electron micrograph of the (111) $\mathrm{D}_{3}$ spot in Fig. 3(a), showing the existence of a tiny $\mathrm{D}_{3}$ ordered phase. Figure 3(d) is the DF electron micrograph of the (200) $\mathrm{D}_{3}$ and (100) $\mathrm{B}_{2}$ spots in Fig. 3(b), showing the existence of $\mathrm{D}_{3}$ and $\mathrm{B}_{2}$ phases. When we compare Figs. $3(\mathrm{c})$ and $3(\mathrm{~d})$, we find that the $\mathrm{B}_{2}$ phase is larger than the $\mathrm{D}_{3}$ phase because the $\mathrm{B}_{2}$ phase is more stable at high temperature. Additionally, the $\mathrm{D}_{3}$ phase precipitates during quenching. The experimental results indicated that the $\mathrm{B}_{2}$ and $\mathrm{D}_{3}$ ordered phases are found within the ferrite owing to the $\alpha \rightarrow \alpha+\mathrm{B}_{2} \rightarrow \alpha+\mathrm{D}_{3}$ ordering transition mechanism. This 
result indicated that an increase in the amount of Al in the Fe-Mn-Al-C alloy would enhance both the formation of ordered phases with the ferrite matrix and the precipitation of $\kappa$-carbides within the austenite matrix. ${ }^{(7,8)}$

Figures 4 and 5 are TEM images of the Fe-15Mn-10Al-1.0C alloy aged at $450{ }^{\circ} \mathrm{C}$ for 24 h. Figure 4(a) is the SADP of the austenite matrix and the foil normal is [011]. It shows the existence of austenite matrix diffraction spots and the precipitate of $\kappa$-carbide diffraction spots. Figure 4(b) is the DF electron micrograph of the (100) $\kappa$-carbide spots in Fig. 4(a), showing the well-grown and newly precipitated $(\mathrm{Fe}, \mathrm{Mn})^{3} \mathrm{AlC}_{X}$ carbides with L'12 crystal structures and

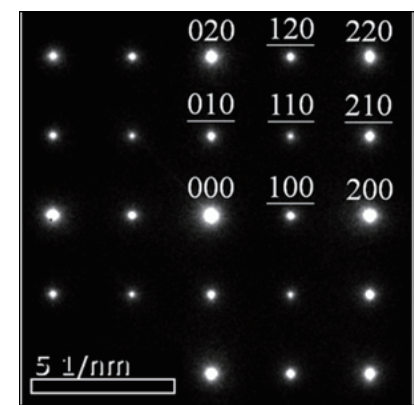

(a)

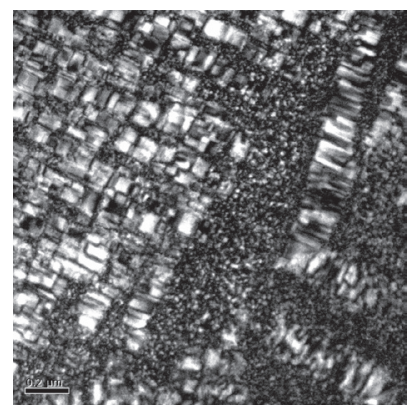

(b)

Fig. 4. TEM images of Fe-15Mn-10Al-1.0C alloy aged at $450{ }^{\circ} \mathrm{C}$ for $24 \mathrm{~h}$. (a) SADP of the austenite matrix. The foil normal is [001]. (b) (100) $\kappa$-carbide DF electron micrograph.

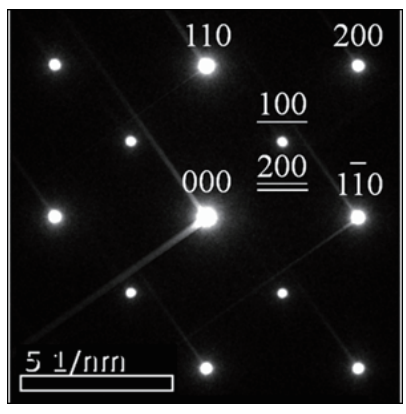

(a)

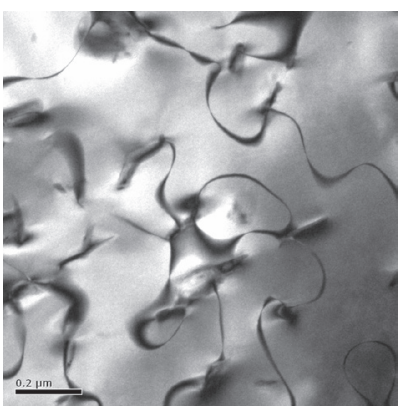

(c)

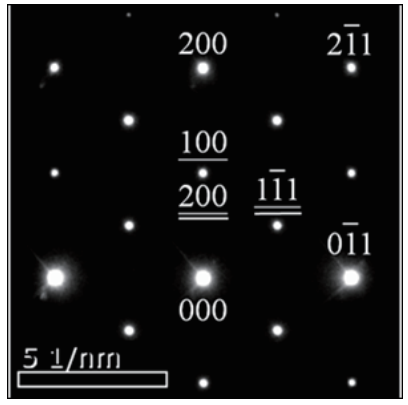

(b)

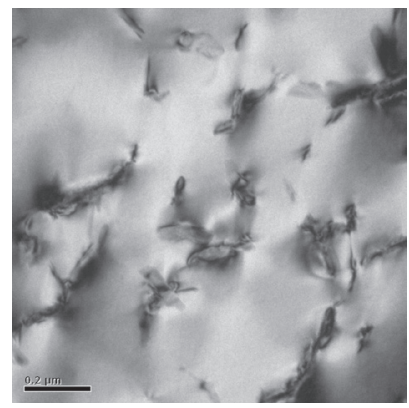

(d)

Fig. 5. TEM images of Fe-15Mn-10Al-1.0C alloy aged at $450{ }^{\circ} \mathrm{C}$ for $24 \mathrm{~h}$. SADPs of the ferrite matrix where (a) the foil normal is [001] and (b) the foil normal is [011]. DF electron micrographs of (c) the (111) $\mathrm{D}_{3}$ phase and (d) the (200) $\mathrm{D}_{3}$ and (100) $\mathrm{B}_{2}$ phases. 
different morphologies within the austenite matrix. Figures 5(a) and 5(b) are SADPs of the ferrite region and the foil normals are [001] and [011], respectively. They show the existence of ferrite matrix diffraction spots and the $\mathrm{B}_{2}$ and $\mathrm{D}_{3}$ precipitate diffraction spots. Figures 5(c) and 5(d) are DF electron micrographs of the (111) $\mathrm{D}_{3}$ and (100) $\mathrm{B}_{2}+(200) \mathrm{D}_{3}$ spots in Figs. 5 (a) and 5(b), respectively. These show that the growth of the $\mathrm{D}_{3}$ ordered phase within the ferrite region is stable, with different morphologies of $\left(\alpha+\mathrm{D} 0_{3}\right)$ phases within the ferrite region.

Figures 6(a) and 6(b) are TEM images of the Fe-15Mn-10Al-1.0C alloy that was aged at 550 ${ }^{\circ} \mathrm{C}$ for $24 \mathrm{~h}$. Figure 6(a) is the DF electron micrograph of the (100) $\kappa$-carbide spot within the austenite matrix, revealing the precipitation of $\kappa$-carbides with an L'12 crystal structure within the austenite matrix. Figure 6(b) is a DF electron micrograph of the (111) $\mathrm{D}_{3}$ spot within the ferrite matrix, showing the existence of only the $\mathrm{D}_{3}$ phase. No $\mathrm{B}_{2}$ phase within the ferrite matrix could be observed. It can be seen that the stable temperature of the $\mathrm{D}_{3}$ phase is below approximately $550{ }^{\circ} \mathrm{C}$.

Figure 7(a) is an optical micrograph of the Fe-15Mn-10Al-1.0C alloy aged at $650{ }^{\circ} \mathrm{C}$ for 24 $\mathrm{h}$, which shows the austenite phase decomposition. Figure 7(b) is a bright-field (BF) electron micrograph of the austenite grain boundary, showing rod-like $\kappa^{\prime}$-carbides within both the austenite grain boundary and the ferrite mixture. Figure 7(c) is the SADP electron micrograph of the region marked $\mathrm{P}$ near the carbides, showing the existence of ferrite matrix diffraction spots and the precipitate of $\mathrm{B}_{2}$ and $\mathrm{D}_{3}$ diffraction spots. Figure $7(\mathrm{~d})$ is the $\mathrm{DF}$ electron micrograph of the (111) $\mathrm{D}_{3}$ spot in Fig. 7(c). It shows that in the Fe-15Mn-10Al-1.0C alloy aged at $650{ }^{\circ} \mathrm{C}$ for $24 \mathrm{~h}$, phase decomposition of $\gamma \rightarrow \kappa^{\prime}+\mathrm{B}_{2}$ could be observed on the austenite grain boundary. It is worth noting that the $\gamma \rightarrow \kappa^{\prime}+\mathrm{B}_{2}$ transformation was quite different from the $\gamma$ $\rightarrow \alpha+\kappa^{\prime}, \gamma \rightarrow \kappa^{\prime}+\mathrm{D}_{3}$, and $\gamma \rightarrow \kappa^{\prime}+\beta$-Mn transformations observed by others. Figures 8(a) and 8 (b) are TEM images of the Fe-15Mn-10Al-1.0C alloy aged at $600{ }^{\circ} \mathrm{C}$ for $24 \mathrm{~h}$. Figures $8(\mathrm{a})$ and $8(\mathrm{~b})$ are the DF electron micrographs of the $\mathrm{D}_{3}$ and $\mathrm{B}_{2}+\mathrm{D}_{3}$ spots within the ferrite mixture, showing the growth of the $\mathrm{B}_{2}$ phase within the ferrite mixture but the beginning of $\mathrm{D}_{3}$ phase decomposition. Figures 9 (a) and 9(b) are DF electron micrographs of the Fe-15Mn$10 \mathrm{Al}-1.0 \mathrm{C}$ alloy aged at $650{ }^{\circ} \mathrm{C}$ for $24 \mathrm{~h}$, which show tiny $\mathrm{D}_{3}$ phases and $\mathrm{B}_{2}$ phases within the ferrite mixture. It can be seen that the transition temperature of the $\mathrm{B}_{2} \rightarrow \alpha+\mathrm{D}_{3}$ ordered transformation was found to be within the narrow range of $600-650{ }^{\circ} \mathrm{C}$, which was quite

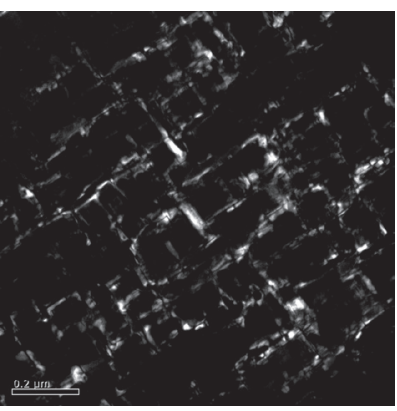

(a)

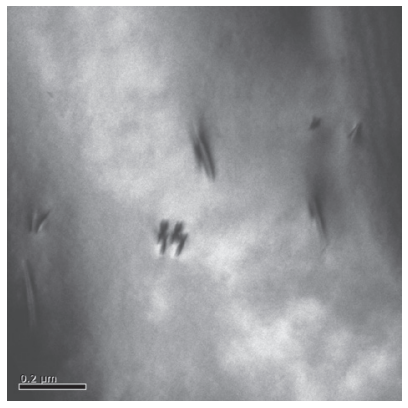

(b)

Fig. 6. TEM images of the Fe-15Mn-10Al-1.0C alloy aged at $550{ }^{\circ} \mathrm{C}$ for $24 \mathrm{~h}$. DF electron micrographs of (a) the (100) $\kappa$-carbide and (b) the (111) $\mathrm{D}_{3}$ phase. 


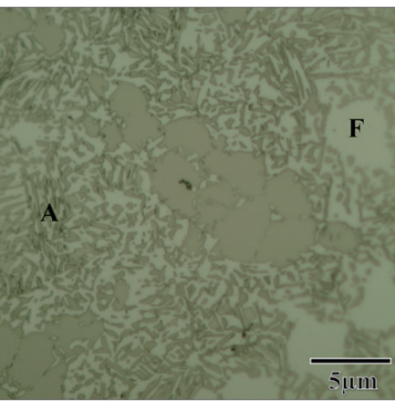

(a)

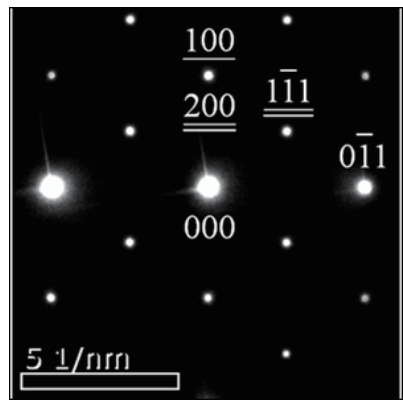

(c)

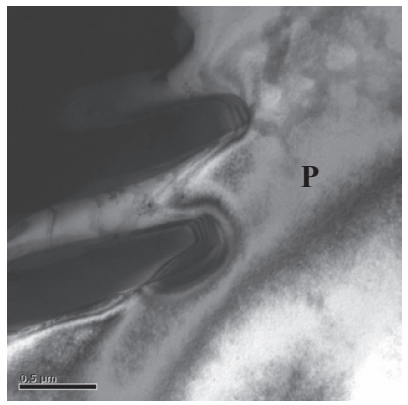

(b)

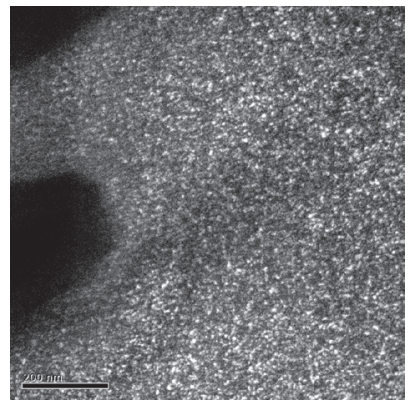

(d)

Fig. 7. (Color online) Fe-15Mn-10Al-1.0C alloy aged at $650{ }^{\circ} \mathrm{C}$ for $24 \mathrm{~h}$. (a) Optical micrograph. (b) BF electron micrograph. (c) SADP of the region marked as P. The foil normal is [001]. (d) (100) $\kappa$-carbide DF electron micrograph.

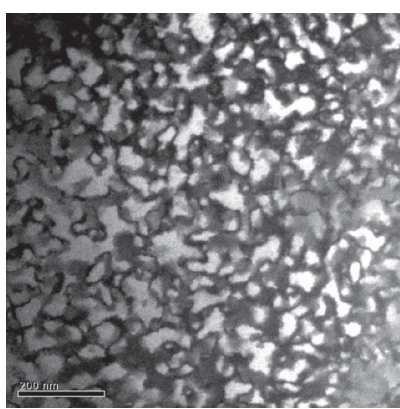

(a)

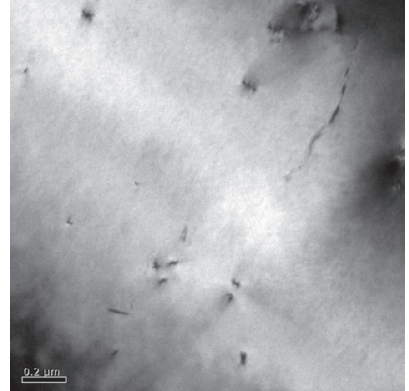

(b)

Fig. 8. TEM images of the Fe-15Mn-10Al-1.0C alloy aged at $600{ }^{\circ} \mathrm{C}$ for $24 \mathrm{~h}$. DF electron micrographs of (a) the (111) $\mathrm{D}_{3}$ phase and (b) the (200) $\mathrm{D}_{3}$ and (100) $\mathrm{B}_{2}$ phases.

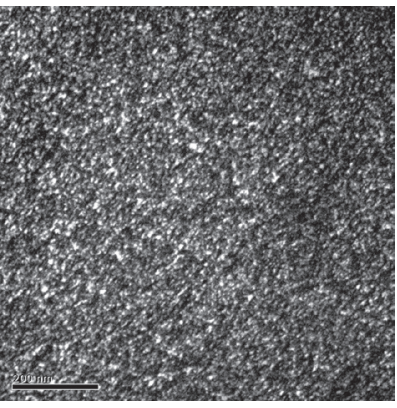

(a)

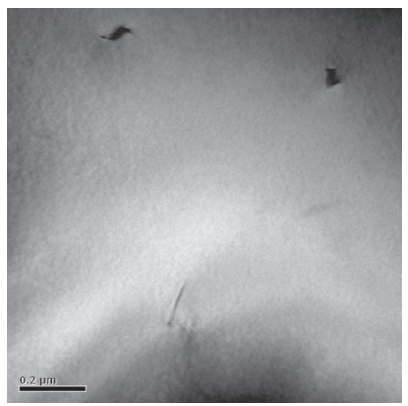

(b)

Fig. 9. TEM images of the Fe-15Mn-10Al-1.0C alloy aged at $650{ }^{\circ} \mathrm{C}$ for $24 \mathrm{~h}$. DF electron micrographs of (a) the (111) $\mathrm{D}_{3}$ phase and (b) the (200) $\mathrm{D}_{3}$ and $(100) \mathrm{B}_{2}$ phases. 
different from the $\alpha \rightarrow \mathrm{B}_{2} \rightarrow \alpha+\mathrm{D}_{3}$ transition previously observed in the Fe-Mn-Al-C alloy by other researchers.

Figure 10 is an optical micrograph of the Fe-15Mn-10Al-1.0C alloy aged at $750{ }^{\circ} \mathrm{C}$ for 24 $\mathrm{h}$, showing the austenite phase decomposition. The microstructure was further observed using a TEM. Figures 11(a) and 11(b) are TEM images of the Fe-15Mn-10Al-1.0C alloy aged at $750{ }^{\circ} \mathrm{C}$ for $24 \mathrm{~h}$. Figure 11(a) is a BF electron micrograph of the area mixed austenite and ferrite. Figure 11(b) is the SADP of the austenite matrix and the foil normal is [011]. It shows the existence of only austenite matrix diffraction spots; no precipitate of $\kappa$-carbide diffraction spots could be observed. It can be seen that the $\kappa$-carbide stability growth temperature range is $450-750{ }^{\circ} \mathrm{C}$, but under the as-quenched condition, the existence of $\kappa$-carbide within the austenite matrix could be observed. Figures 12(a) and 12(b) show energy dispersive X-ray spectroscopy (EDS) spectra obtained from the austenite matrix of the Fe-15Mn-10Al-1.0C alloy aged at $750{ }^{\circ} \mathrm{C}$ for $24 \mathrm{~h}$ and from the austenite matrix of the Fe-15Mn-10Al-1.0C alloy under the as-quenched condition, respectively. The difference between these two EDS spectra could be caused by the presence of manganese. It is clear that austenite matrix of the alloy under the asquenched condition is manganese-rich and has a manganese-to-aluminum ratio of 3:1, which is confirmed by electron diffraction analysis. According to Ref. 5, this result is caused by the $\kappa$-carbide precipitation by spinodal decomposition during quenching.

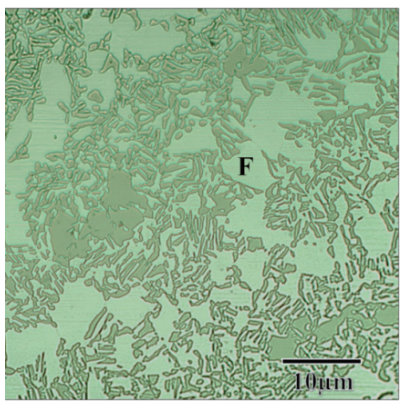

(a)

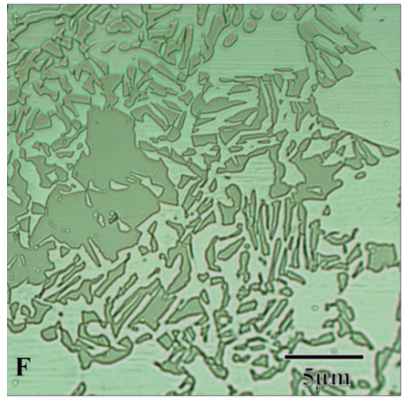

(b)

Fig. 10. (Color online) Optical micrograph of the Fe-15Mn-10Al-1.0C alloy aged at $750{ }^{\circ} \mathrm{C}$ for $24 \mathrm{~h}$. (a) $100 \times$ and (b) $500 \times$.

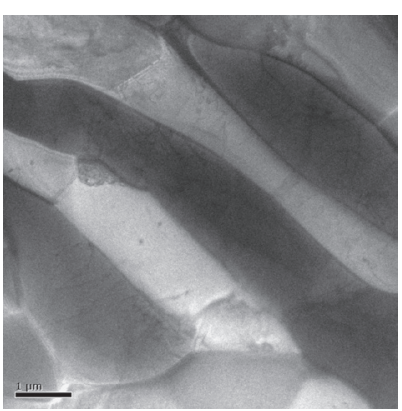

(a)

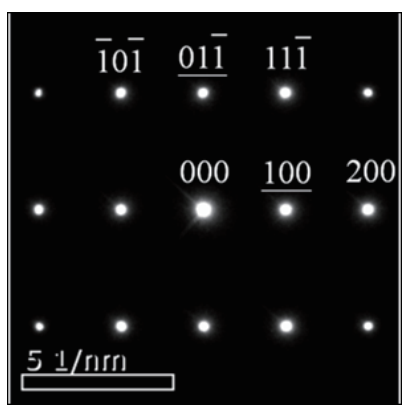

(b)

Fig. 11. TEM images of the Fe-15Mn-10Al-1.0C alloy aged at $750{ }^{\circ} \mathrm{C}$ for $24 \mathrm{~h}$. (a) BF electron micrograph. (b) SADP of austenite matrix. The foil normal is [011]. 


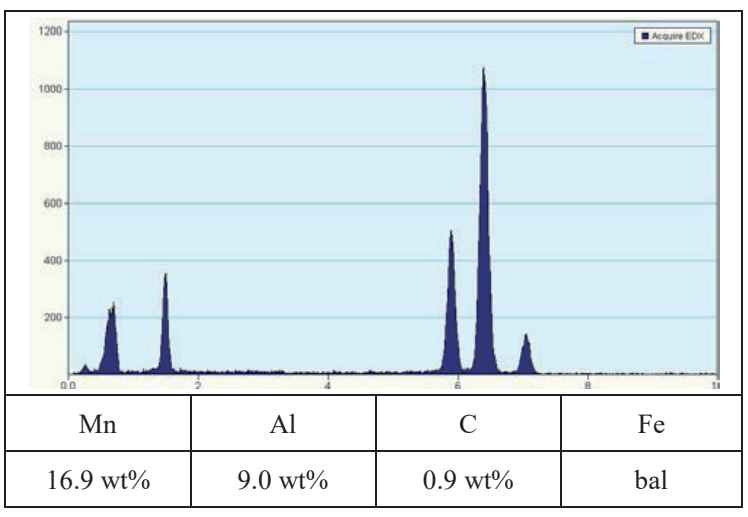

(a)

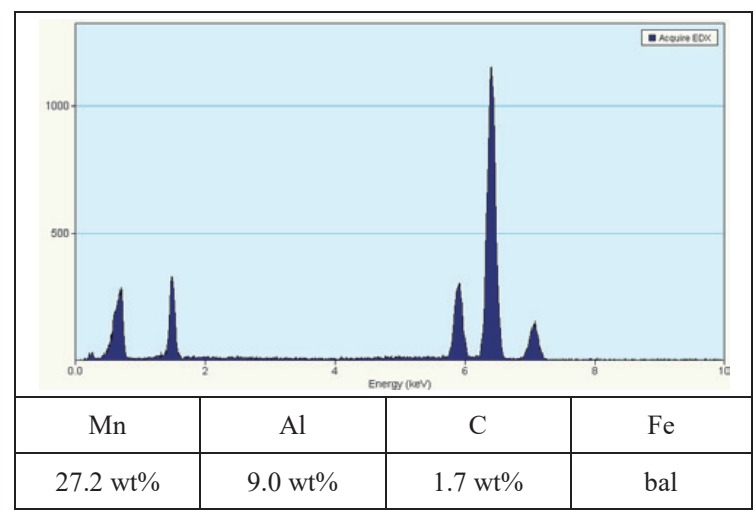

(b)

Fig. 12. (Color online) EDS spectra obtained from the austenite matrix of Fe-15Mn-10Al-1.0C alloy. (a) EDS spectrum of austenite matrix under the as-quenched condition and (b) EDS spectrum of the austenite matrix aged at $750{ }^{\circ} \mathrm{C}$ for $24 \mathrm{~h}$.

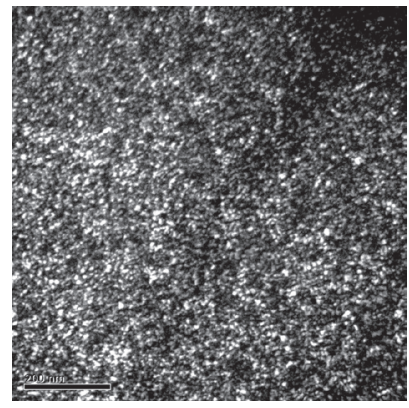

(a)

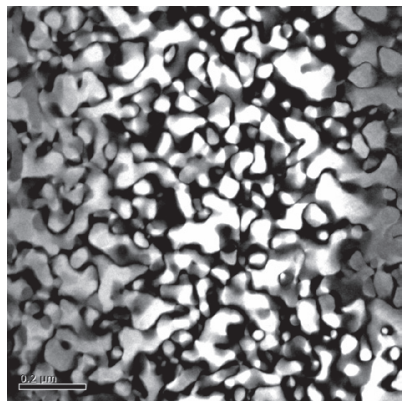

(b)

Fig. 13. TEM images of the Fe-15Mn-10Al-1.0C alloy aged at $750{ }^{\circ} \mathrm{C}$ for $24 \mathrm{~h}$. DF electron micrographs of (a) the (111) $\mathrm{D}_{3}$ phase and (b) the (200) $\mathrm{D}_{3}$ and (100) $\mathrm{B}_{2}$ phases.

Figure 13(a) is the DF electron micrograph of the $\mathrm{D}_{3}$ phase within the ferrite mixture, showing the existence of a tiny $\mathrm{D}_{3}$ ordered phase. Figure $13(\mathrm{~b})$ is the DF electron micrograph of the $\mathrm{D}_{3}$ and $\mathrm{B}_{2}$ phases, showing the existence of the $\mathrm{B}_{2}$ phase. This microstructure is similar to that under the as-quenched condition. Experimental results indicated that when the $\mathrm{Fe}-$ $15 \mathrm{Mn}-10 \mathrm{Al}-1.0 \mathrm{C}$ alloy was aged at 450 to $750{ }^{\circ} \mathrm{C}$, the ordering phase transformation of $\alpha \rightarrow \mathrm{B}_{2}$ $\rightarrow \alpha+\mathrm{D}_{3}$ occurred within the ferrite region. The transition temperature of the $\mathrm{B}_{2} \rightarrow \alpha+\mathrm{D}_{3}$ ordered transformation was found to be within the narrow range of $550-600{ }^{\circ} \mathrm{C}$, which was quite different from the $\alpha \rightarrow \mathrm{B}_{2} \rightarrow \alpha+\mathrm{D}_{3}$ transition observed in the Fe-Mn-Al-C alloy by other researchers.

\section{Conclusions}

1. When the Fe-15Mn-10Al-1.0C alloy was aged at $450{ }^{\circ} \mathrm{C}$ for 24 to $72 \mathrm{~h}$, the growth of the $\mathrm{D}_{3}$ ordered phase within the ferrite region revealed stable $\left(\alpha+\mathrm{D} 0_{3}\right)$ phases with different morphologies within the ferrite region. Additionally, well-grown and newly precipitated 
$(\mathrm{Fe}, \mathrm{Mn})^{3} \mathrm{AlC}_{X}$ carbides with L'12 crystal structures with different morphologies could be observed within the austenite matrix.

2. When the Fe-15Mn-10Al-1.0C alloy was aged at $650{ }^{\circ} \mathrm{C}$ for $24 \mathrm{~h}$, the phase decomposition of $\gamma \rightarrow \kappa^{\prime}+\mathrm{B}_{2}$ could be observed on the austenite grain boundary. It is worth noting that the $\gamma \rightarrow \kappa^{\prime}+\mathrm{B}_{2}$ transformation was quite different from the $\gamma \rightarrow \alpha+\kappa^{\prime}, \gamma \rightarrow \kappa^{\prime}+\mathrm{D}_{3}$, and $\gamma \rightarrow \kappa^{\prime}+\beta$-Mn transformations observed by other researchers.

3. When the Fe-15Mn-10Al-1.0C alloy was aged at 450 to $750{ }^{\circ} \mathrm{C}$, the ordering phase transformation of $\alpha \rightarrow \mathrm{B}_{2} \rightarrow \alpha+\mathrm{D}_{3}$ occurred within the ferrite region. The transition temperature of the $\mathrm{B}_{2} \rightarrow \alpha+\mathrm{D}_{3}$ ordered transformation was found to be within the narrow range of $550-600{ }^{\circ} \mathrm{C}$, which was quite different from the $\alpha \rightarrow \mathrm{B}_{2} \rightarrow \alpha+\mathrm{D}_{3}$ transition observed in the Fe-Mn-Al-C alloy by other researchers.

\section{References}

1 C. N. Hwang, C. Y. Chao, and T. F. Liu: Scr. Mater. 28 (1993) 263.

2 C. S. Wang, C. N. Hwang, C. G. Chao, and T. F. Liu: Scr. Mater. 57 (2007) 809.

3 C. C. Wu, J. S. Chou, and T. F. Liu: Metall. Trans. A 22 (1991) 2265.

4 Y. Kimura, K. Handa, K. Hoyashi, and Y. Mishima: Intermetallics 12 (2004) 607.

5 Inoue, T. Minemure, A. Kitamura, and T. Masumoto: Metall. Trans. A 12 (1981) 1041.

6 C. S. Wang, C. N. Hwang, C. G. Chao, and T. F. Liu: Scr. Mater. 57 (2007) 809.

7 G. Frommeyer, H. J. Habrock, J. E. Wittig, J. Geenen, and M. Kreuss: Scr. Metall. 24 (1990) 51.

8 Y. L. Lin and C. P. Chou: Scr. Metall. 28 (1993) 1261. 